\title{
Hacia una comunidad de América del Norte: TLCAN plus o ASPAN
}

DOI: $10.32870 /$ mycp.v10i28.285

Elizabeth Vargas García*

\section{Introducción}

$\mathrm{E}$ 1 primero de enero de 2004 se cumplieron los primeros diez años de la entrada en vigor del Tratado de Libre Comercio de América del Norte (TLCAN), con el cual México dio inicio a su transformación en una de las economías más abiertas del mundo. Por tanto, es claro que el TLCAN puede considerarse como un parteaguas en las relaciones de México en el ámbito internacional.

La firma del Tratado con Estados Unidos y Canadá conllevó un fuerte contenido político y simbólico, ya que marcó una nueva era en la construcción de la integración económica internacional que la distinguió de los anteriores acuerdos de integración regional firmados en América Latina e incluso en otras partes del mundo.

Cuando en 1994 entró en vigor el TLCAN, no se consideraba en el futuro cercano la posibilidad de que entrara en un proceso tendiente a traspasar o sumar temas al del libre comercio. A doce años de ese suceso, las cosas han cambiado notablemente: en el presente existen planes y expectativas que muestran que la región de América del Norte se convertirá en algo más que un área destinada únicamente al comercio libre. Los acontecimientos del 11 de septiembre dieron un vuelco a la situación en el continente; se ha entrado en una nueva

* Investigadora del Departamento de Estudios Internacionales, cucsh-Universidad de Guadalajara. dinámica donde el tema de lo económico sigue siendo prioritario, fundamentalmente por las ventajas que el comercio y la inversión representan, pero ahora ha sido enlazado de manera muy estrecha con el tema de la seguridad. Ambos temas - comercio y seguridad - se configuran en esta etapa como aquellos sobre los que girará la fórmula de relaciones bilaterales y trilaterales.

El objetivo de este trabajo es analizar cómo se está llevando a cabo la dinámica de la integración regional para el caso de América del Norte, y cómo el TLCAN se ha convertido en un acuerdo base tendiente a conducir a esta parte de la región a esquemas de integración de mayores alcances y profundidad.

\section{Los inicios del tLCAN y los factores de su emergencia}

Los tres países que conforman el TLCAN tuvieron razones tanto internas como externas que motivaron su emergencia. El ingreso de México a este esquema se justificaba de manera interna por el agotamiento del modelo sustitutivo de importaciones, y su incapacidad de generar un crecimiento económico sostenido; por la posibilidad que ofrecía el libre comercio de crear mayor número de empleos de manera interna, pues la intención de México era exportar bienes y no mano de obra; y por los resultados positivos que se obtuvieron cuando México entró al esquema de la política neoliberal 
en cuanto a la reducción de aranceles al comercio exterior, la promoción de las inversiones exteriores, el control de la inflación y el gasto público. ${ }^{1}$

Para Estados Unidos representaba la oportunidad de sobrepasar sus problemas económicos derivados de la recesión por la que cruzaba, del déficit público alto y del dólar sobrevaluado. Aunado a ello, el alto grado de proteccionismo canadiense demostraba detener y obstaculizar el desarrollo de las industrias y los capitales estadounidenses. Del mismo modo, Canadá se topa con trabas originadas, a su vez, por el proteccionismo del mercado estadounidense.

El punto de confluencia para los tres países, además del panorama antes descrito, estuvo en las razones externas, ya que los procesos de globalización y la nueva era en la conformación de bloques comerciales representaban riesgos muy altos para aquel que quisiera competir de manera individual en el mercado internacional. La Comunidad Europea, por ejemplo, evolucionó hacia la Unión Europea, acuerdo que derivó del original hacia el estadio de integración más alto hasta ahora conocido y que englobó la unión económica, política y monetaria. Por su parte, Asia encontró el punto de convergencia exitoso con su entorno al contar con Japón como pivote en el proceso que se denomina regionalismo abierto. Es decir, tanto "tigres" como "dragones" se insertaron en el esquema, atraídos por el poderío financiero y técnico japonés. ${ }^{2}$ La integración asiática se tipificó como una alianza en la que, si bien no medió ningún tratado, el objetivo que se perseguía era claro: hacer competir a sus integrantes en la economía mundial para ganar espacios comerciales y financieros. ${ }^{3}$ Por tanto, al tener la región de América del Norte un acuerdo previo entre Canadá y Estados Unidos, se amplió hacia México y se creó una nueva área con el Tratado de Libre Comercio de América del Norte (TLCAN). América del Sur estaba en efervescencia buscando nuevas rutas para avanzar y hacer más eficientes sus proyectos, como el Mercosur, por ejemplo.

El TLCAN se convirtió, el mismo año que entró en vigor, en lo que se ha considerado como "el primer paso" hacia la propuesta de gran envergadura que constituyó el ALCA. La creación de una Área de Libre Comercio de las Américas fue resultado de las cumbres de las Américas iniciadas con la de Miami. El ALCA debía proveer un acceso libre al mercado de bienes y servicios para todo el continente. Se decidió que las negociaciones no deberían concluir más allá del año 2005. Es decir, se tenía previsto que para ese año el ALCA (de concretarse los planes) fuera una realidad. Sin embargo, las controversias en lo que respecta a la forma de ver y de actuar en torno a las negociaciones del ALCA, protagonizadas principalmente por Estados Unidos y Brasil, no se dirimieron en el tiempo esperado y el ALCA no prosperó.

\section{Los avances en la negociación trilateral entre México, Estados Unidos y Canadá}

\section{Antecedentes de la Asociación para la Seguridad y la Prosperidad en América del Norte (ASPAN)}

Después del Tratado de Libre Comercio que México firmó con Estados Unidos y Canadá y que vincula a los tres países en los aspectos comercial y económico, han surgido distintas iniciativas cuyos objetivos son fortalecer, consolidar e incrementar acciones de cooperación para lograr una región más próspera y más segura. La declaración 
de Quebec de abril de 2001, aun y cuando surgió en el marco de las negociaciones del ALCA y cuyo alcance geográfico abarcó a casi a todo el continente con la reserva de Venezuela, ya contemplaba áreas más allá de las meramente comerciales. ${ }^{4}$

Dentro de la relación bilateral en América del Norte, un antecedente que se restringió a lo estrictamente comercial y a la inversión, pero con tendencias a estrechar la relación trilateral (México, Estados Unidos y Canadá), lo fue la Sociedad para la Prosperidad, iniciativa de los presidentes George W. Bush y Vicente Fox, de septiembre de 2001. La Sociedad respondió al interés por crear y consolidar una agenda de cooperación entre ambos países para propiciar el potencial económico de los ciudadanos de la región mediante el libre comercio y la inversión. ${ }^{5}$ La iniciativa se enfocó en la creación de alianzas entre el sector público y el sector privado para "potenciar los recursos, experiencias y compromisos del sector privado, para impulsar el crecimiento económico y la creación de empleos en las regiones menos desarrolladas de México". ${ }^{6}$

La conformación de la Sociedad avanzó de manera rápida, ya que para el año 2002 los dos mandatarios, aprovechando el marco de la Cumbre de la onu en Monterrey, dieron a conocer el plan de acción en donde se definieron la visión, la misión y los objetivos. Para noviembre de ese mismo año se presentó el primer reporte de los trabajos de la Sociedad.

Otra iniciativa importante fue la Alianza para la Frontera México-Estados Unidos, signada en marzo de 2002. Fue dada a conocer por el entonces secretario de Gobernación de México, Santiago Creel, y por el Secretario de Estado de Estados Unidos, Colin Powell, e incluyó un plan de acción que especificó los pormenores para crear una frontera eficiente con base en tecnología de punta y una estrecha cooperación entre los dos países. La creación y puesta en marcha de esta alianza facilitaría el intercambio comercial entre los dos países y promovería el cruce legítimo de la frontera. ${ }^{7}$ Una alianza similar entre Estados Unidos y Canadá precedió a la Sociedad para la Prosperidad entre Estados Unidos y México, si bien una diferencia importante está en que en la primera el plan de acción consta de 22 puntos, en tanto la segunda cuenta con 30 puntos. $^{8}$ Ambas alianzas tienen en común la creación de un perímetro de seguridad con el fin de reforzar la seguridad fronteriza de Estados Unidos con Canadá y de Estados Unidos con México.

Como se puede apreciar, aun y cuando las alianzas tienen como objetivo básico el reforzamiento del comercio y la inversión, ya desde inicios de la década hay cierta tendencia a incluir el renglón de la seguridad como parte de los acuerdos e iniciativas. Del mismo modo, estos mecanismos han surgido como una alternativa para "ensanchar" la integración de América del Norte, a la vez que son los antecedentes de lo que hoy conocemos como TLCAN Plus o ASPAN.

La Asociación para la Seguridad y la Prosperidad en América del Norte refleja el lugar primordial que ocupa el tema de la seguridad para Estados Unidos y, por ende, la influencia que ello tiene en sus re- 
laciones con Canadá y México. A partir de los acontecimientos del 11 de septiembre de 2001, la búsqueda de los mecanismos en ese sentido se han intensificado; ${ }^{9} \mathrm{y}$ ahora, con la ASPAN, se conjuntan los temas comerciales y de seguridad.

Ahora bien, sabemos que el TLCAN se constituye como la piedra angular de la integración de la parte norte del hemisferio, y que la ASPAN es el producto de las relaciones político-diplomáticas que se han venido registrando desde el año 2001 y hasta hoy día. Ambos mecanismo están estrechamente vinculados, y más precisamente, el segundo replantea en gran medida al primero, como se podrá ver en el siguiente apartado.

\section{La Asociación para la Seguridad y la Prosperidad en América del Norte: ASPAN O TLCAN plus}

Según la versión oficial, la ASPAN es un proceso permanente cuyo objetivo es la búsqueda y el establecimiento de mayor nivel de integración de América del Norte, Por medio de esta alianza, los tres países (Canadá, Estados Unidos y México) compartirán dos temas básicos: la Agenda de la prosperidad con la que se prevé y se promoverán el crecimiento económico, la competitividad y la calidad de vida; y la Agenda de seguridad, en la que se pretende desarrollar un enfoque común en esa materia con la finalidad de instalar un perímetro de protección en América del Norte.

Para dar seguimiento de la ASPAN se crearon inmediatamente grupos de trabajo en función de los dos temas. Se procedió a la instalación de mesas redondas con actores de distintos sectores, reuniones con los grupos empresariales y sesiones informativas con los legisladores e instancias políticas incidentes de los tres países. El resultado fue una serie de acciones tendientes a incrementar la competitividad de esta parte de la región. ${ }^{10}$

De estos temas específicos de la Agenda para la prosperidad llama particularmente la atención el primer renglón: las reglas de origen y aranceles, donde se asienta claramente en su desglose que se negociará un segundo paquete en reglas de origen establecidas en el TLCAN, el acuerdo de un tercer paquete previsto para el corto plazo y la creación de los mecanismos necesarios para que estas modificaciones sean aplicadas en breve. Es decir, la ASPAN se configura como el mecanismo de vinculación al TLCAN, por medio del cual el nivel de integración se profundizará y se ensanchará hacia el área de la seguridad. Así, el art. 102 del TLCAN en su última fracción consigna: "establecer lineamientos para la ulterior cooperación trilateral, regional y multilateral encaminada a ampliar y mejorar los beneficios de este Tratado". ${ }^{11}$

De los puntos de la Agenda de seguridad, el segundo gran tema aborda la amenaza que representa el terrorismo y dibuja algunas de las rutas que se deberán seguir para combatirlo; en el renglón de las amenazas trasnacionales se menciona el tema ampliamente debatido, pero sin solución aún: el retorno de los indocumentados. No hace referencia alguna a la construcción del muro antiinmigrantes.

En la declaración conjunta se anota que "por definición, la Alianza es trilateral pero permite que dos países, de manera bilateral, avancen en un tema, y abran el camino para que el tercero se sume más adelante". ${ }^{12}$ La asimetría es clara y significa que los temas no se negociarán de manera trilateral uniformemente, sino que los socios irán estableciendo rutas bilaterales de acuerdo con sus alcances. Esto se 


\section{Cuadro 1}

\section{Los grandes temas sobre los que girará la ASPAN}

\begin{tabular}{ll}
\hline Temas de la agenda de prosperidad & Temas de la agenda de seguridad \\
\hline Se enfoca en: & Se enfoca en: \\
-Aumentar la productividad. & -Proteger a la región de América del Norte contra \\
-Reducir los costos del comercio y los costos de & amenazas externas. \\
transacción. & -Prevenir y responder a amenazas dentro de la región \\
-Promover de manera conjunta mayor & de América del Norte. \\
corresponsabilidad con nuestro medio ambiente. & -Aumentar la eficiencia del tránsito seguro de bajo \\
-La creación de una oferta de alimentos más confiable & riesgo a través de nuestras fronteras compartidas. \\
y segura, que facilite a la vez el comercio de productos & \\
agrícolas. & \\
-La protección de nuestra población contra & \\
enfermedades. &
\end{tabular}

Fuente: Elaboración propia con base en la información de la página de la SRE. http://www.sre.gob.mx.

\section{Cuadro 2}

Los temas específicos para cada uno de los dos grandes rubros

\begin{tabular}{ll}
\hline Agenda de prosperidad & Agenda de seguridad \\
\hline -Reglas de origen y aranceles. & Tres grandes temas: \\
-Facilitación de negocios. & 1. Protección de América del Norte contra amenazas \\
-Bienes industriales. & externas: \\
-Medidas sanitarias y fitosanitarias. & -Seguridad para viajeros de alto riesgo \\
-Biotecnología agrícola. & -Seguridad para carga. \\
-Comercio electrónico y biotecnologías de la & -Bioseguridad. \\
información. & 2. Prevención y respuesta a amenazas dentro de \\
-Transporte. & América del Norte: \\
-Servicios financieros. & -Seguridad aérea. \\
-Energía. & -Seguridad marítima. \\
-Medio ambiente. & -Amenazas trasnacionales. \\
-Salud. & -Lucha contra el terrorismo, \\
-Capital humano. & -Protección de infraestructura crítica, \\
& 3. Aumentar la eficiencia del flujo seguro de tránsito \\
& de bajo riesgo a través de nuestras fronteras \\
& compartidas \\
& -Zonas aeroportuarias libres de inspección: \\
& -Reducción de tiempos de espera. \\
\hline
\end{tabular}

Fuente. Elaboración propia con base en información de la página de la SRE. http://www.sre.gob.mx.

puede constatar en los dos reportes a los mandatarios, elaborados para dar cuenta de los progresos del proyecto ASPAN de junio de 2005 y de 2006.

La ASPAN se vislumbra como la renegociación ampliada del TLCAN con el acento puesto en el tema de la seguridad. Esto último, sin duda, causa controversias y genera más preguntas que respuestas, ya que, por ejemplo, ¿dónde queda el tema migratorio? La pretensión es la homogenización de un enfoque en materia de seguridad, lo cual nos generaría un enorme problema en materia de inmigrantes, sobre 
todo si adoptamos el enfoque de Estados Unidos.

\section{Conclusiones}

1. Sin duda esa ruta que México inició al lado de Estados Unidos y Canadá, al parecer no tiene retorno, más bien se puede hablar de esquemas que buscan definir con mayor exactitud el área geográfica de América del Norte mediante un programa de integración ampliado en temas y en profundización de los ya existentes.

2. Con los acontecimientos del $11 \mathrm{de}$ septiembre, el tema de la seguridad se ha convertido en prioritario y convergente; y en éste, Estados Unidos funge como pivote entre Canadá y México. Sin embargo, las perspectivas y los requerimientos de cada uno de los tres países son diferentes. Es de todos conocido que Estados Unidos no nada más desea, sino que necesita controlar sus fronteras para protegerse contra el terrorismo, también es cierto que México desea y busca una frontera más flexible, sobre todo en el renglón de los indocumentados: aquí el desencuentro entre México y Estados Unidos es palpable y no se vislumbra en el corto plazo una solución; incluso puede llegar a ser paradójico pensar en un perímetro de seguridad común de América del Norte pero con un muro entre México y Estados Unidos. Por tanto, la convergencia en materia de seguridad fronteriza es una de las materias en las que la cooperación trilateral deberá trabajar y no la solución a la compleja problemática.

3. El camino hacia una integración de mayor alcance en Norteamérica se percibe todavía como incierto. Si bien en los documentos oficiales revisados se habla de un avance rápido en la profundización de los esquemas de libre comercio del TLCAN, todavía no hay claridad acerca de hasta dónde se quiere llegar. Se habla de la creación de una comunidad, pero para llegar es imprescindible pasar por varios estadios de integración que no se vislumbran en el corto plazo, pues la conjunción entre los socios es totalmente asimétrica y los mecanismos y las propuestas para acercar a los menos favorecidos son difusos.

4. La ASPAN emerge apuntalada por dos visiones. Por un lado, el reconocimiento de la estrecha interdependencia entre los tres países que la conforman y su posicionamiento geopolítico en el mundo, y por el otro, en una visión optimista, el reconocimiento de que la cercanía es un factor que debe ser aprovechado en beneficio mutuo mediante la cooperación y la creación de esquemas que den respuesta a un mundo cada vez más globalizado.

5. El TLCAN es la columna vertebral de los proyectos de integración liderados por Estados Unidos. Se alcanza a proyectar que de convertirse la ASPAN en una realidad, se propondría como vínculo para otros esquemas de integración del continente y de alguna manera avanzar hacia América Latina en la otra alternativa a los objetivos planteados por el ALCA. ח?

\section{Notas}

1. Velásquez, Flores Rafael. "Orígenes, objetivos y estructura institucional del TLCAN". En: Retos e interrelaciones de la integración regional: Europa y América. Coordinadores: Joaquín Roy, Roberto Domínguez R. y Rafael Velásquez Flores. Universidad de Quintana Roo y Plaza y Valdés. México, 2003. P. 224-225. 
2. Zapata, Martí Ricardo. "De la geopolítica a la geoeconomía tendencias y perspectivas de la regionalización”. En: El nuevo sistema internacional. Una visión desde México. SRE y FCE. México, 1999. P. 48

3. Idem.

4. Declaración de Quebec. Marzo de 2001. Quebec, Canadá.

5. http://www.p4pworks.org/p4p. php?seccion=antecedentes

6. Ídem.

7. http://www.migracioninternacional.com/

8. Sandoval, Palacios Juan Manuel. "El área de libre comercio de las Américas (ALCA) y la nueva seguridad regional hemisférica. En www.boelllatinoamerica.org/

9. En la búsqueda de los mecanismo de seguridad, hay que recordar que en el año 2002 se creó el Comando del Norte con la misión de disuadir, prevenir y vencer amenazas y agresiones dirigidas a su territorio e intereses Estadounidenses. El área geográfica que cubre el Comando del Norte abarca desde Alaska hasta México y su responsabilidad está en salvaguardar la seguridad por aire, tierra y mar.

10. Reporte a los mandatarios. Junio de 2005. En http::www.SRE.com.mx

11. Referencia extraída del Tratado de Libre Comercio de América del Norte. Artículo 102: Objetivos. Los objetivos del presente Tratado, expresados en sus principios y reglas, principalmente los de trato nacional, trato de nación más favorecida y transparencia, son los siguientes: a) eliminar obstáculos al comercio y facilitar la circulación transfronteriza de bienes y de servicios entre los territorios de las Partes; b) promover condiciones de competencia leal en la zona de libre comercio; c) aumentar sustancialmente las oportunidades de inversión en los territorios de las Partes; d) proteger y hacer valer, de manera adecuada y efectiva, los derechos de propiedad intelectual en territorio de cada una de las Partes; e) crear procedimientos eficaces para la aplicación y cumplimiento de este Tratado, para su administración conjunta y para la solución de controversias; y f) establecer lineamientos para la ulterior cooperación trilateral, regional y multilateral encaminada a ampliar y mejorar los beneficios de este Tratado.

12. Declaración conjunta México, Canadá, Estados Unidos, hecha el 23 de marzo de 2005. Waco, Texas.

\section{Bibliografía}

Balassa, Bella. Teoría de la integración económica. Uteha. México, 1970.

Declaración conjunta México, Canadá, Estados Unidos, hecha el 23 de marzo de 2005. Waco, Texas.

http://www.american.edu/ia/cnas/pdfs/workingpaper2_celorio_es.pdf

http://www.sre.gob.mx

http://www.migracioninternacional.com/

http://www.p4pworks.org/p4p.php? seccion=antecedentes

Reporte a los mandatarios. Junio de 2005. En http://. www.sre.com.mx

Sandoval, J. M. "El área de libre comercio de las Américas ( ALCA) y la nueva seguridad regional hemisférica. En www.boell-latinoamerica.org/

Saxe, J. 2006. "México-Estados Unidos: seguridad y colonialidad energética". En Nueva Sociedad, 204. Julio-agosto.

Velásquez, R. 2003. "Orígenes, objetivos y estructura institucional del tLCAN". En: J. Roy, R. Domínguez y R. Velásquez (coords.), Retos e interrelaciones de la integración regional: Europa y América. Universidad de Quintana Roo, Plaza y Valdés. México.

Zapata, R. 1999. "De la geopolítica a la geoeconomía: tendencias y perspectivas de la regionalización". En: El nuevo sistema internacional. Una visión desde México. SRE y FCE. México. 


\section{Series \\ Pacific Rim: \\ Globalization, Regionalization, and Domestic Trajectories}

Under the general supervision of Melba E. Falck and Arturo Santa Cruz and edited by Universidad de Guadalajara and University of Technology Sydney
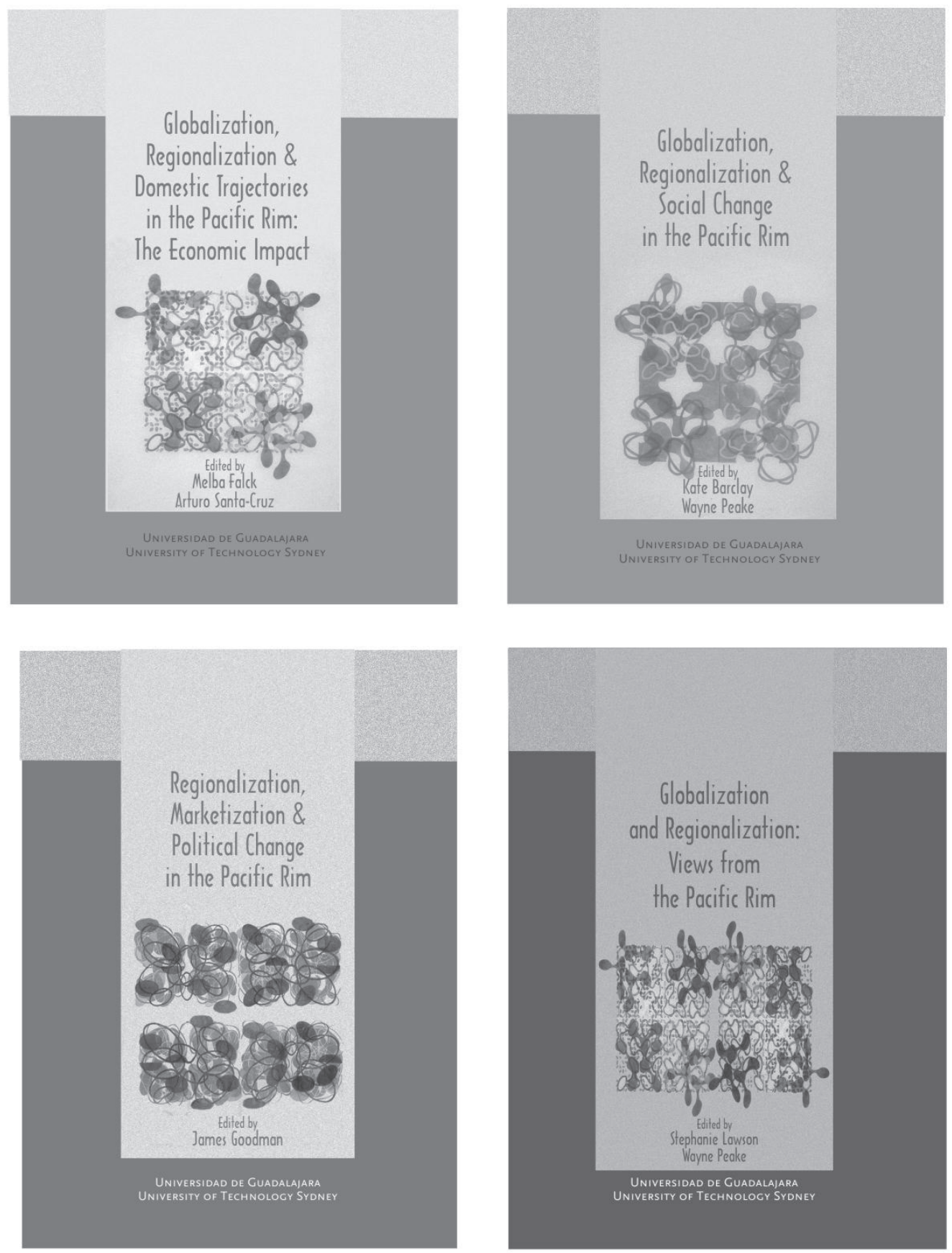